Schmidt M., Purwins S. (2018): Simultaneity as a challenge for development. In:

GeoJournal 83, 1193-1204. DOI: https://doi.org/10.1007/s10708-017-9828-1/0

\title{
Simultaneity as a challenge for development
}

Matthias Schmidt .and Sebastian Purwins

\begin{abstract}
Societies in the Global South are simultaneously confronted with various challenges that societies in the Global North faced over a long period of time. From the beginning of the 18th century the Global North has faced challenges in line with its industrialization and modernization processes including population growth with the necessity to feed that growing population, rapid urbanization or infrastructure development. Solving these challenges during past centuries has led to highly developed societies but produced new threats: environmental degradation and climate change-features of Beck's 'reflexive modernity'. Today, societies in the Global South not only face similar challenges such as population growth, malnutrition or lacking infrastructure, but also the consequences of the humanmade environmental change and its related risks. Change in the Global South has reached a previously unseen pace and notable simultaneity. This paper aims to operationalise and visualise the challenge of simultaneity. By identifying six indicators for three main issues, the extent of simultaneity will be analysed using the examples of Kenya, India, Brazil and Germany. The findings show that simultaneity is a key challenge for current social, economic and ecological transformations in the Global South.
\end{abstract}

Keywords Simultaneity__Global South_Acceleration_ Development

\section{Introduction}

Hunger, disease and war have always been major problems of humankind, affecting populations throughout all centuries and regions (Harari 2017). While the latter is the result of political processes, the emergence of hunger and disease are closely connected with socioeconomic and technological developments. Consequently, these three curses strike people very differently depending upon space and time, or more precisely on political, social, economic and technological achievements. Today, hunger and epidemics are not a big issue in highly developed societies of the Global North but they have been in the past. The solving of these problems took a lot of time and effort. Socio-economic and technological developments helped to overcome these challenges but eventually created new ones. For example, innovations of the Industrial Revolution and afterwards helped to eradicate diseases, to increase yields and to produce better and cheaper consumer goods but they also induced new challenges related to population growth and rapid urbanization with the well-known side effects of poor housing, epidemics and other social and health problems. Although the mentioned problems were largely tackled in the Global North, others are not: the resource intensive economic development produced new threats and risks such as environmental degradation and climate change. Humankind is confronted with the aftermaths of its own achievements-features of Beck's (2007) 'reflexive modernity'. The situation for societies in the Global South, the so-called developing countries, is different. Many nations of the Global South are still confronted with hunger and disease; they are challenged with feeding their growing populations and resolving major health issues, but also in managing rapid urbanization processes and establishing infrastructures. Additionally they are 
confronted with the new risks of the reflexive modernity; environmental degradation and climate change-generated mainly in the Global North. This means that societies in the Global South are faced with a large multitude of threats and challenges at the same time. For example, the population of Nigeria increased in 2017 by $2.4 \%$, the cities grew between 2010 and 2015 at a rate of $4.6 \%$; 31\% of Nigeria's population have no access to improved water sources and $71 \%$ are lacking sanitation facilities (WHO and UNICEF 2015; CIA Factbook 2015a, b, c, d, e). The list is long and could be extended. In addition to these tremendous challenges, however, Nigeria faces the consequences of climate change and rising environmental degradation. While the Global North is largely responsible for accelerated environmental change in the course of its industrialization and modernization, people in the Global South are the most affected by these environmental risks. It becomes obvious that certain challenges, that the Global North could cope with over time, occur more rapidly and simultaneously in countries of the South. This simultaneity, as a set of challenges, presents itself as a completely new issue that the North has never experienced so far. The UN Expert Group (2008: 3) notes: "The simultaneity of these historical changes constitutes what could be characterized as the foremost sustainability nexus of the 21st century". This article wants to outline the concept of simultaneity according to transformations in the Global South. We argue that societies in the Global South are nowadays confronted with a multitude of burdens, problems and challenges simultaneously which represents a new and unique situation since societies in the Global North tackled similar challenges over a significant time-span of several centuries. To visualize the simultaneity of challenges, we have chosen and defined three orders and six indicators which were tested by using four countries as examples, those being Kenya, India, Brazil and Germany, each representing a specific stage according to the Human Development Index. The goal of our paper is foremost to highlight the major, but largely neglected problem of simultaneity for developing countries and to offer a way to visualise this phenomenon. The article is divided into three parts; the first section elaborates on the concept of simultaneity; the second part deals with possible indicators that illustrate simultaneity as a development challenge; and the last part exemplifies the simultaneous challenges through country examples and raises questions for future research. We are using a secondary analysis with data from the free accessible datasets of the World Bank and the UN to establish our indicators.

\section{Contextualizing simultaneity}

According to the classic modernisation theory (Rostow 1991), development is a process running in steps on a time-scale. Modernisation started in Europe and has led to highly developed societies. The countries of other world regions just have to follow this path; still they seem to be some steps behind but on a linear pathway, sometimes winding a way towards development. It is widely accepted that some developmental steps could be reached in a much shorter time or even be skipped, while others are more difficult to achieve. In general, development and modernisation seem to occur more and more rapidly in recent times, although Jean-Jacques Rousseau had already documented the social change and its acceleration during the political upheaval in France at the end of the 18th century. More recently Gleick (1999) proclaimed in his publication Faster: The acceleration of just about everything that the experience of an accelerated world became the essence of modernity. Conrad (1999, p. 9) argues that "modernity is about the acceleration of time", whereas Eriksen and Nielsen (2001, p. 159) concisely define "modernity is speed". Rosa (2005) argues that the temporal structures of a society are characterised by a subjective feeling of acceleration. He describes acceleration as the "increase in quantity per unit of time" (Rosa 2005, p. 115), which can refer to goods and their production as well as to social life. The process of acceleration leads to increasingly complex actions, the destruction of linear and successive sequences, as well as the coexisting rise in activities, challenges and influences (Rosa 2010). But what is missing in the idea of modernisation and acceleration is the consideration of the simultaneity of development challenges; simultaneity receives less attention or in a different context. For example, in the 1980s the concept of simultaneity became a formula capable of combining 
tradition and modernity. The simultaneity of the non-simultaneous means undergoing different developmental stages at the same time (Bloch 1985). In most cases, however, this only refers to the juxtaposition of new technologies and traditional structures. Through the process of acceleration, there is an increasing complexity of actions, the breaking down of linear and successive sequences as well as the increasing simultaneity of activities, challenges and influences (Rosa 2005). In his systems theory, Luhmann (1984) deals extensively with simultaneity and synchronisation. While biological systems constitute a comprise of stable elements and units in space, social systems are regarded as emergent units of the temporal dimension. The understanding of time in traditional societies is characterised by the differences between the past and the future, while with modernisation these differences are dissolved (Esposito 2007). According to Luhmann (2003) although the past has been regarded as the past and the future as the future, these boundaries began to blur at the end of the 20th century. The temporal phenomenon of simultaneity means that the present appears as a complex network of many present points. A time interval between a cause and a subsequent effect is no longer present. For Luhmann $(1990,2005)$, the central problem seems to lie in a society's need for reconciliation, the question how simultaneous phenomena can be coordinated. Harvey (1989) provides in his theory of time-space compression a plausible explanation for the acceleration and compression caused by capitalism; however, he does not directly deal with the simultaneity of processes that accompanies it. Marcotullio (2004) builds on these assumptions and proposes the concept of time-space telescoping, which characterises the "collapsing, compression and telescoping of previously experienced sequential development patterns" (Marcotullio 2004, p. 32). He argues that while the urban environmental priorities of developed countries originally focused on so-called brown issues (water quality), moving onto to grey issues (air and chemical pollutants) and now green issues (sustainability), many developing countries are simultaneously confronted by all three environmental priorities. Marcotullio (2004) analyses and compares urban environmental conditions of cities in the United States with Asian cities. He concludes that time and space related effects have created a different and unique context for cities in the Global South; challenges occur sooner, faster and more likely simultaneously (as a set of problems) than previously experienced in the Global North. Through the influence of globalisation, many challenges appear in Asian cities at the same time as opposed to US cities which faced major challenges sequentially and, thus, were able to test different approaches and to adapt to various situations (Marcotullio 2004; Marcotullio et al. 2005). Whittaker et al. (2008, p. 1) focus on what they call compressed development, which is defined as "development that unfolded over the span of a century [...] and has been compressed into even shorter periods in more recent developers". Using the example of Taiwan they emphasize the simultaneous occurrence of industrialization and de-industrialization; "the result of the compression is not just a blurring of stages, but simultaneous industrialisation and deindustrialisation" (Whittaker et al. 2008, p. 9). However, the role of environmental change and the challenges of a preindustrial society do not play an important role in the approach of compressed development; the focus is on the processes of industrialisation and the embedding in global value chains. The mentioned approaches have in common, that they describe a compressed development that leads to the simultaneous occurrence of certain processes that have taken place sequentially in countries of the Global North; for Whittaker et al. $(2008$, p. 4) with a socalled "collapsing of development stages". Building on these assumptions of simultaneity as a set of challenges, below we discuss and suggest indicators to operationalise the concept.

\section{Methodology: operationalisation of simultaneity}

In a secondary analysis, we operationalise what we understand as simultaneous challenges for current societies in the Global South. For Medjedovic' (2014) the potential of secondary analysis lies in understanding the past, understanding change, examining problems comparatively, improving general knowledge through replication and enlargement, elevating and enlarging theory. The merging of different data sets is one way in which the transformation of social phenomena can be studied. 
Secondary analysis is thus an important method of theory formation, especially on macro-sociological processes. We have chosen six indicators, with each representing a specific task related to essential human needs. Each represents a challenge that can be related to a specific stage, here called an order, within the modernisation process that historically occurred consecutively in the so-called developed countries of the Global North. However, this does not mean to expect or even demand that all societies follow a specific modernisation path according to the modernisation theory (Rostow 1991) or a specific development paradigm. Rather, the indicators represent fundamental elements needed for positive human development irrespective of the political system or tasks that aim to reduce harm to the environment, as it is seen as indispensable for the survival of humankind.

\section{Identifying orders and indicators}

The first order represents development patterns of a preindustrial society. Important tasks for preindustrial societies are used to safeguard basic needs. Consequently, major efforts are needed in key fields, for example, food security, access to drinking water, sanitation, appropriate accommodation, or general health and education standards. Solving these problems is a fundamental requirement for the whole socioeconomic system and the livelihoods of households and individuals. The second order reflects the challenges of a transition from an agrarian society to an industrial (Fordist) society. These challenges arise as a result of modernisation, such as the change from a rather traditional society to a more complex society. Third order challenges are those that arose as a result of industrialisation and globalisation. They are characterised by the fact that they have a global reach and have been significantly accelerated and caused by the economic development (and success) of the Global North. According to Beck (2007), these challenges are consequences of the 'reflexive modernity'. Modernity is confronted with its own aftereffects; thus, problems can no longer be solved by usual methods (Bo"hle and Weihrich 2009). Uncertainty and ambiguity are particularly evident in environmental risks. They are the result of the industrial production and consumption patterns of the North. The fact that these risks occur on a global scale means that they challenge the Global North and the Global South at the same time; however, the magnitude of the challenges is different. Societies in the Global South, in general, are confronted by more severe risks than societies in the Global North although the latter are the main polluters. Databases of the United Nations and its suborganizations, the World Bank and the US Central Intelligence Agency are used for our data analysis. These records are freely accessible and updated at regular intervals. The indicators used, correspond to the most current level, which relates to the year 2014 or 2015 depending on the indicator. We have selected only those indicators, which have met the following premises: explicitness, availability and comparability. Explicitness means that the indicator does not consist of further indicators because the more indicators are aggregated the higher the total number of errors. The premise of availability means that the data is freely accessible and could be reviewed by anyone. Comparability implies that the indicators should all be recorded and displayed in the same unit of measure. In addition, the indicators for more than $80 \%$ of the countries should have been collected in order to be able to compare several countries accordingly. In the preparation of the indicator set, certain indicators were rejected from the model after consideration of the assumptions. The chosen indicators and their selection will be explained in the following sub-chapters.

\section{First order indicators}

First order indicators are derived from questioning whether basic needs (defined as the minimum resources necessary for physical well-being) can be ensured. Food and water, shelter and clothing are traditionally seen as immediate basic needs (Denton 1990), in addition to sanitation, education and healthcare. We have chosen improved sanitation and access to electricity as indicators, which are prerequisites for improved living conditions and for realising educational opportunities. 
Access to clean drinking water and sanitation is an important prerequisite for good health and, thus, for further developments. Consequently, this aspect is one of the UN's 17 Sustainable Development Goals (SDG); "By managing our water sustainably, we are also able to manage our production of food and energy and contribute to decent work and economic growth" (UN 2016, p. 2). Access to drinking water and sanitation improves health and living conditions. It reduces the spread of diseases, especially diarrheal diseases, but also dracunculiasis and forms of inflammation, such as trachoma. As a result of diarrheal diseases, two million people worldwide die annually, more than half of the hospital beds available are occupied by affected patients. 10,000 people die each year due to Schistosoma, a disease caused by worms or bacteria which is spread through contaminated water (Bartram et al. 2005; Hopkins 2005). By providing access to sanitation facilities diarrheal diseases can be reduced by $21 \%$. It is estimated that in 46 countries around the world more than half of the population has no access to sanitation facilities, and more than 800 million people have no access to clean drinking water (UNDP 2016). Increasing urbanisation and traffic, industries and intensified forms of farming lead to the depletion of groundwater resources and the pollution of water reserves. Lacking water treatment and insufficient forms of water storage are major problems. It is mainly women who are responsible for fetching water which is, in many regions of the world, still a laborious and time-consuming task. Women carry heavy water canisters on their heads for hours (Schmidt and Pearson 2016), which not only stresses their bodies but also prevents young girls from attending school (Sobsey 2002). The United Nations argues that no other development objective can be achieved without access to clean drinking water and sanitation. Access to electricity The WHO (2016) estimates that more than three billion people cook or heat with wood, coal or even hazardous waste on an open fire site in their homes. This results in an increase in air pollutants and leads to harmful health problems. According to the WHO (2016), 4.3 million people die each year as a result of diseases caused by indoor air pollution. Access to electricity can reduce this form of pollution and associated diseases (OECD 2006). Today, electrification is a major challenge in the Global South, as opposed to European and North American cities that were connected to a power grid from the 1880s onwards (Ehrhardt and Kroll 2012). Electricity in households helps to improve educational opportunities, as those students with power are able to do their homework and learn during twilight or at night time. According to a study by UNICEF (2015) about $90 \%$ of children in sub-Saharan Africa go to a primary school that is without electricity. The study also highlights the fact that non-electrified schools cannot use modern media tools in the classroom.

\section{Second order indicators}

The second order represents the challenges that occur in connection with industrialisation and urbanisation processes. Both processes are important drivers of economic, environmental and social change. As indicators, we have chosen the percentage of the urban population living in slums and the proportion of the labour force in the agricultural sector.

\section{Population in slums}

Industrialisation in Europe led to rapid urbanisation processes that came along with the expansion of cities and the development of quarters with poor housing conditions and insufficient infrastructure. Hosting large amount of migrants from the rural areas was a decisive challenge for European cities in the 18th and 19th century. As a result of prosperity and modern technologies this challenge was eventually overcome (UN Habitat 2003). Currently, poor housing conditions and slums are a rather minor problem in cities of the Global North but a distinct characteristic of urban agglomerations in the Global South. Debt, poverty and the lack of jobs are forcing the rural population to move to the cities, hoping for better living conditions. Due to a lack of living space, the informal settlements that grow rapidly at the outskirts of cities do not have sanitation facilities or access to clean drinking water, 
problems similar to those faced in the urban centres of Europe during the 19th century (Davis 2006; Huchzermeyer 2014). However, the speed of urbanisation and the sheer size of several megacities in Asia and sub-Saharan Africa are enormous. According to the World Population Review 2017, the population of Lagos, Nigeria, grew from 762,000 in 1960 to 10 million in 2010, and will probably reach 15 million inhabitants in 2017; it is estimated that the Lagos area grows by more than 600 people per minute (Agbola and Agunbiade 2009). Such rapid urbanisation goes along with rapid slum development (UN Habitat 2016a, b), especially on the outskirts and often in the immediate vicinity of landfill sites. Slums are characterised by high levels of poverty and unemployment; the informal sector is particularly strong, and social problems such as crime or drug abuse are also intense (Davis 2006).

\section{Labour force in the agricultural sector}

Usually, the structural change of an economy is described by Fourastie"s three-sector model. It shows that with advancing socio-economic development the agricultural sector is replaced by the industrial sector and later by the growing service sector. While many countries in the Global North underwent such a succession, these processes currently are shifted in the Global South. Economies in sub-Saharan Africa still show low industrialisation rates and are characterised by a proportionately high agricultural and (informal) service sector. A distinctive informal sector is emerging in urban areas, offering people the chance to sustain their livelihoods through casual work or other kinds of services. However, the agricultural sector itself is also changing. Peasants or small farmers have to compete with an intensified, mechanised agriculture characterised by monocultures on large sites. Agriculture in the Global South is still the primary employment sector, which still comprises a large subsistence component, meaning that many farmers can only sell a small percentage of their crops at local markets (FAO 2017).

\section{Third order indicators}

The third order represents the challenges that the Global South as well as the Global North now face: climate change and environmental degradation. These challenges are characterised by the fact that they have been significantly accelerated, above all, by the economic development of the Global North. According to Beck (2007), they are consequences of the 'reflexive modernity'; modernity is confronted with its own negative consequences. Although the societies of the Global North are, for the largest part, responsible for climate change and environmental degradation, the consequences and risks are global. However, the Global South cannot react in the same way as European or North American countries, which have developed over time into stable economies. This makes certain countries more vulnerable than others. "Of the ten most affected countries by climate change (1995-2014), nine were developing countries in the low income or lower-middle income country group, while only one (Thailand) was classified as an uppermiddle income country" (Kreft et al. 2015). The high amount of nitrogen fertilisers in agriculture and the share of power generation that utilise renewable energy sources were chosen to be the two indicators. The first relates to a negative side effect of the enormous increase in yields, and the second to the latest strategy of decarbonisation, to replace fossil resources in electricity generation by renewable sources.

Nitrogen fertilisers in agriculture

Nitrogen is an elementary nutrient for living organisms. Its use as fertiliser is critically relevant for increasing yields. With the development of the Haber- Bosch process in 1910, it became possible to obtain ammonia from elementary air nitrogen. This facilitated the large-scale production of synthetic fertiliser and increased industrial agriculture since the 1960s. To this day 80 million tonnes of air nitrogen are converted into reactive nitrogen annually for fertiliser production (Umweltbundesamt 2011). The nitrogen used leads to a faster growth of the plants and higher yields, which is necessary in view of the rising population numbers. However, if too much nitrogen is discharged, the so-called 
nitrogen surplus escapes into water bodies or remains in the ground and causes extensive environmental problems, such as eutrophication and acidification of soils, vegetation stress, biodiversity loss, and even health risks for humans (Umweltbundesamt 2011). In view of the mentioned health and environmental problems that arise as consequences of excessive nitrogen use, industrialised as well as developing countries have to rethink industrial agriculture. But in order to export more foods or to become independent of food imports, governments worldwide are trying to increase agricultural yields; still mainly using nitrogen fertilisers. The proportion of nitrous oxide emissions (dinitrogen monoxide) is used as an indicator for environmental degradation and relates to aspects of climate change and food security. The problematic consequences affect both the Global North and the Global South.

Power generation from renewable energy sources

The burning of fossil fuels to generate electricity is connected with the release of large quantities of carbon dioxide. To reduce greenhouse gas emissions and to achieve environmentally friendly economic growth, many countries are transferring their energy production towards renewable energy sources (WBGU 2003). At the end of 2015 at the UN Climate Conference in Paris, the world community decided to keep global warming below 2 _C. This means that all nations will need to significantly reduce their greenhouse gas emissions. In order to achieve this goal, the consumption of fossil fuels would have to almost completely be abandoned by 2040 and must be replaced by renewable energies. In addition, each country would have to reduce its emissions by 55\%. In 2016, 175 states from both the Global North and the Global South accepted this agreement (UNFCCC 2015). However, introducing renewable energies and the ability of governments to subsidise power generation from renewable energy sources present tremendous differences between the Global North and the Global South. The consequences of industrialisation and the consumption of fossil fuels are seen as an important factor of the anthropogenic induced climate change. The amount of renewable energy sources can be seen as an indicator that describes how national economies cope with the risks of the reflexive modernity by introducing and supporting renewable energy technologies.

\section{Analysis: visualised simultaneity in selected country examples}

Data bases belonging to the United Nations as well as statistics from the World Bank and the US Central Intelligence Agency were used to calculate and further to visualise the simultaneity of challenges. The results of our calculations for each indicator are presented in a network diagram, while each indicator was given a value between 0 and 100\%. The network diagram represents several indicators of each country and compares the countries with each other. Here, the larger the area, the more challenges the respective country faces at the same time.

To prove and exemplify our argument we selected four countries that have different development stages. For this we followed the United Nations Human Development Index (HDI) which considers income per capita, life expectancy at birth and education indicators. The United Nations Development Programme divides all countries into four groups which are characterised as very high (developed), high (developing), medium (developing) and low (undeveloped) in terms of their HDI value. In order to visualise simultaneity and global differences we selected one country from each group.

Kenya is the example of a country with a low HDI. Although Kenya is regarded as a regional power in East Africa and has experienced a positive economic development in recent years, it still faces serious problems meeting basic human needs such as poverty reduction, health care and sanitation. Despite its economic growth, the targeted millennium goals have not yet been achieved in Kenya.

India was chosen to represent the medium category. Since 1990, India has undergone significant economic growth each year, but economic imbalances between regions and social groups are 
extremely high. Around half of India's population still depends on agriculture, hundreds of millions live in poverty and malnutrition rates are high. Population growth, industrialisation and urbanisation processes are among the main causes of rising environmental problems (Houscht 2016).

From countries with a high HDI, Brazil, the seventh-largest economy in the world was chosen. The basis of economic development is, besides a strong domestic market, the export of raw materials. However, Brazil is also characterised by socioeconomic inequalities, which have a strong influence on development (Kiegel 2017).

An example of a country categorised as very high is Germany. With a GDP of 3.4 trillion US\$ (2015), Germany is the largest economy in Europe and the fourth largest in the world. According to the HDI, in 2015 Germany occupied the sixth place and, thus, is considered to be a country with a very high standard of living.

The network diagram (Fig. 1) compares the four described countries; the larger the polygon the higher the simultaneity of challenges. The proportion of the population without access to sanitation facilities is very high ([50\%) in Kenya and India. In Brazil, this is around $18 \%$ and in Germany it is zero, as the expansion of sanitary facilities has been at an advanced standard for a long time. Although Germany still needs to spend significant financial resources to maintain and renew water supplies and sewage systems, the existing infrastructure is highly efficient. Establishing and improving sanitation, thus, is a fundamental challenge particularly for Kenya and India. The proportion of the population with no access to electricity is highest in Kenya (70\%) followed by India (20\%) while almost all inhabitants of Brazil and Germany have access to electricity. In Kenya the urban electrification rate is at $60 \%$ while in the rural areas it is only 7\% (International Energy Agency's World Energy Outlook 2016). Poor living conditions and slums are a major challenge for Brazil, India and particularly Kenya. Around $22 \%$ of Brazil's urban population live in slums, $24 \%$ of India's urban population and more than half of all urban citizens in Kenya. In Kenya's capital Nairobi, more than $60 \%$ of the population live in slums (Parry et al. 2012). Due to the fast growing urbanisation rates, this problem will not be solved in the near future.

The proportion of the population working in the agricultural sector is highest in Kenya. Agriculture remains the backbone of Kenya's economy, contributing to 30\% of the GDP in 2014 and employing almost $80 \%$ of the population. The proportion of the agricultural sector is also very high in India with around 50\%, low in Brazil and extremely low in Germany. At the same time, all selected countries are increasingly using nitrogen as fertilizer, which is why the percentage of nitrous oxide emissions in total emissions in Kenya, Brazil and Germany extends $50 \%$ and continuously grows. The use of fertiliser is necessary to ensure food security but nitrogen oxide is 300 times more damaging to the climate than $\mathrm{CO} 2$ emissions. Thus, it is an important task for the Global North and the Global South alike to reduce these emissions. However, in spite of growing populations, Kenya and India in particular need to increase their agricultural output. The percentage of fossil fuels used for the production of electricity is high, especially in India (69\%), Germany (46\%) and Kenya (42\%). While Germany is able to transform its electricity production by moving towards renewable energies, India and Kenya will have more difficulties due to lacking financial and technical means and other structural problems. The amount of electricity created by fossil fuels is already relatively low in Brazil since the country produces about $80 \%$ of its electricity by hydropower. However, hydropower generation in Brazil is vulnerable due to sporadically occurring severe droughts, resulting in power failures. With the expansion of wind turbines, Brazil has been able to diversify the producer structure and had set up 140 wind parks by 2013 (Juárez et al. 2014).

\section{Discussion}

By analysing recent data and calculations with a focus on six indicators the results show that countries of the Global South are nowadays confronted with a multitude of challenges simultaneously. Obviously 
every country is challenged by various problems and tasks that have to be tackled at the same time, but the amount of challenges varies significantly between the countries in the study. Germany has the smallest polygon, followed by Brazil and India, while Kenya clearly has the largest. As a highly developed and wealthy nation, Germany faces almost no challenges from the first and second order indicators. This means that Germany can concentrate its resources on resolving problems and tasks derived in the third order indicators category, resources that mirror Germany's efforts towards the decarbonisation of its economy and

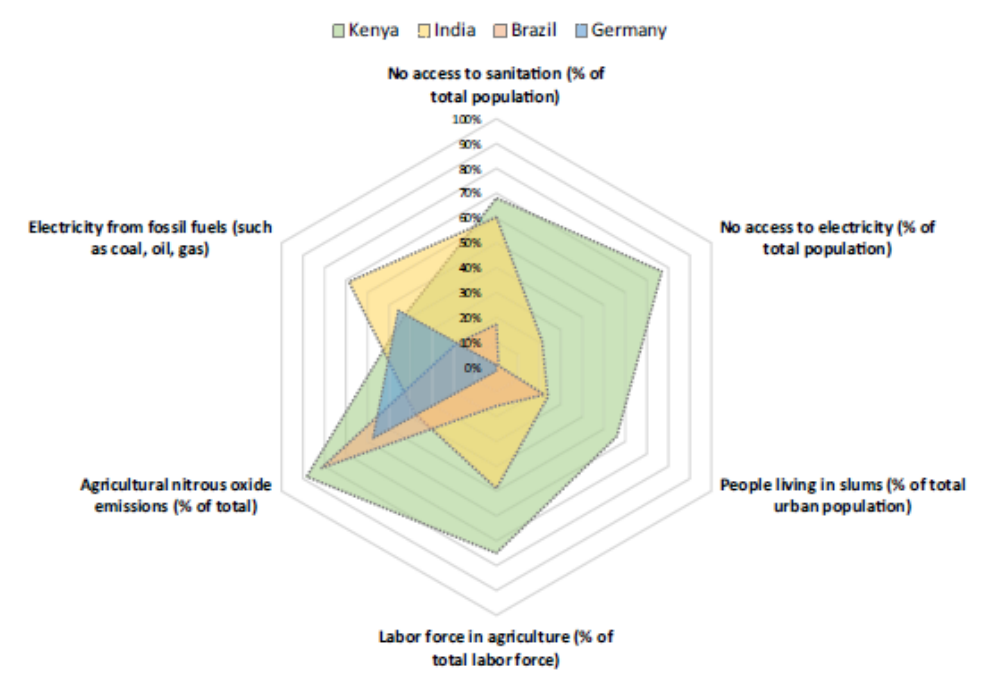

Fig. 1 Visualized simultaneity of selected countries; Kenya, India, Brazil and Germany (Data base: The World Bank 2017; UN 2016; World Factbook CIA 2015a, b, c, d, e). The data refers to the latest state of the survey: 'No access to sanitation' in 2015, 'No access to electricity' in 2012, 'People living in slums' in 2014, 'Labour force in agriculture' in 2012, 'Agricultural nitrous oxide emissions' in 2008, 'Electricity from fossil fuels' in 2014

improving its environmental situation. Brazil's most severe challenge, as a country with abundant natural resources and as important exporter of agricultural products, is related to its agricultural nitrogen emissions. A further problem Brazil faces is the high percentage of people living in slums. Countries with a medium HDI, here India, face challenges in all three orders: low and poor sanitation facilities and communities lacking electricity supply; the socio-structural change from an agrarian society to an industrial or service society; and the high percentage of people living in slums. All these serious challenges are accompanied by the task to transform India's economy into one that is more environmentally friendly. The same holds true for Kenya but to a much greater extent. Kenya, compared to the other countries, has the highest numbers in five of the six indicators. This means it deals with a set of challenges from all of the three orders. This makes the interdependences even more complex. The processing of socioeconomic problems, such as poverty, unemployment or income inequality, is primarily pursued through economic growth. Such a strategy is a challenge to a changing and increasingly degraded environment, which currently threatens particularly countries in the Global South. This simultaneity of challenges, as a set of challenges, creates specific circumstances for development in those countries.

\section{Discussion of methodology}

The selection of the indicators and their relevance for the different societies have already been explained and justified, however, a critical reflection of the methodological approach identified some additional aspects that need to be considered. First of all, data availability is crucial. There might be other, more appropriate and compelling indicators to show the relevance of simultaneity but they could not be used due to a lack of data. Thus, our selection of indicators is considerably guided by the availability of data. The second point focuses on the validity of data. The quality of data and data 
gathering vary between indicators and between each country example. For some indicators, for instance, the share of urban population living in slums is only an approximation as no data has been produced that provides the real number of people living in such environments; in addition to the fact that the definition of a slum is far from unambiguous and may vary from one country to the next. The third point highlights how up-to-date the data is. Data used for some of the indicators are not regularly collected and updated. Therefore, the data used for the indicators in our diagram should be understood as tendencies or approximations rather than as finite facts. Another critical point is the selection of the country examples. Kenya, India and Brazil are mainly classified as Global South, however tend to have different levels of exposure to the various challenges. Due to high heterogeneity between countries results are heavily dependent on the choice of the country examples, which means that it is impossible to come to a conclusion that is valid for the Global South in general. Figure 1 showed that the challenge of simultaneity differs not only between the Global North and South, but also within the Global South.

Further research could possibly find new patterns or explanations in a comparison between and within the countries of the Global South. With the identification of indicators, however, an attempt was made to increase the understanding of the phenomenon of simultaneity. Previous approaches were based either only on theoretical assumptions or could not develop solid indicators. Thus, our network diagram is a visualisation and approximation to the divergent challenges and dynamic processes in the Global South. In order not to think of the concept in patterns of modernisation theory, it is important to recognise that the challenges the Global South are facing simultaneously may seem to be the same as in previous experiences of developed countries, but occur under different circumstances and therefor articulate differently. The circumstances are different, because the development of the Global South cannot be conceived without the development of the North and the reciprocal dependencies. As mentioned, some challenges are produced by the North and especially affect the countries of the Global South. Furthermore, these challenges reached a new level of quality, speed and impact. Therefore, the challenges in both quality and quantity are different from previous experiences, which is why we argue that simultaneity is a key challenge for transformations in the Global South.

\section{A challenge only for the Global South?}

Our analysis shows that risks, burdens or challenges are global and that all societies are confronted with similar ones but that the magnitude of them varies significantly in time and space. In countries of the Global South different challenges are getting greater priority than in the Global North and vice versa. What we wanted to show is that primary challenges that form the basis of each development are still very severe in the Global South and have to be tackled at the same time. This requires efforts and endeavours, which are then diverted away from solving other problems.

The analysis does not mean that countries of the Global North are not confronted with a multitude of challenges - the opposite is the case. But on the basis of their highly developed economies, their abundance of financial and human resources, they are able to tackle these challenges more easily, and they do not have the need to deal with primary basic problems and their consequential issues. The fact that since modern times and at the latest since colonial times the Global North is further developed and one or several steps ahead leading to accelerated developments but also intensified problems in the Global South and thus the need for simultaneous problem solving. For the Global South it is almost impossible to catch up, though some economies such as the PR China show impressive developments but is nowadays confronted with the new burdens of environmental destruction and climate change. However, simultaneity can also be seen as an opportunity. To what extent simultaneity means in sum a higher burden, or to what extent the Global South benefits from technological developments in the Global North to solve, for example, specific health problems or nutrition problems, is difficult to assess and needs further analyses. 


\section{Conclusion}

This article discussed simultaneity as a key challenge for current transformations in the Global South. We argued that a multitude of problems, tasks and challenges that confronted societies in the Global North in a historical, more or less linear process confront societies of the Global South simultaneously or at least in a historically compressed form. These problems are compounded by the more recent challenges of environmental degradation and climate change, which are attributes of the reflexive modernity. We have shown that the challenge of pre- industrial societies, the processes of industrialisation and modernisation as well as anthropogenic environmental change are becoming compressed in a historical context in the Global South, and occur in a new form of simultaneity that the Global North never experienced. Meanwhile, although, the Global North is responsible for accelerated environmental change, environmental degradation and climate change, it is the countries of the Global South that struggle to improve living conditions and to generate prosperity, and are the countries most affected by these environmental challenges.

Simultaneity and its complexity cannot be fully known and results are uncertain. The inner context is a result of the simultaneity of a multitude of uneven practices, processes and decisions, leading to a particular pattern that the article has tried to outline. Future research should try to apply further relevant data as well as consideration of evidence gathered from a greater variety of different countries. Furthermore, the dynamic processes and interactions in the Global South have to be taken into account in order to investigate the causes and effects of simultaneity.

\section{References}

Agbola, T., \& Agunbiade, E. M. (2009). Urbanisation, slum development and security of tenure: The challenges of meeting Millennium Development Goal 7 in Metropolitan Lagos, Nigeria. In A. de Sherbinin, A. Rahman, A. Barbieri, J.-C. Fotso, \& Y. Zhu (Eds.), Urban population- environment dynamics in the developing world: Case studies and lessons learned (pp. 77-106). Paris: Committee for International Cooperation in National Research in Demography.

Bartram, J., Lewis, K., Lenton, R., \& Wright, A. (2005). Focusing on improved water and sanitation for health. Lancet, 365(9461), 810-812.

Beck, U. (2007). Weltrisikogesellschaft. Auf der Suche nach der verlorenen Sicherheit. Frankfurt am Main: Suhrkamp.

Bloch, E. (1985). Erbschaft dieser Zeit. Frankfurt am Main: Suhrkamp.

Böhle, F., \& Weihrich, M. (2009). Ungewissheit, Uneindeutigkeit, Unsicherheit - Braucht die Theorie reflexiver Modernisierung eine neue Handlungstheorie? In F. Böhle \& M. Weihrich (Eds.), Handeln unter Unsicherheit (pp. 9-21). Wiesbaden: Springer.

Central Intelligence Agency (2015a). Nigeria. Central Intelligence Agency. 18 August 2017.

Central Intelligence Agency (2015b). Kenya. Central Intelligence Agency. 18 August 2017.

Central Intelligence Agency (2015c). Germany. Central Intelligence Agency. 18 August 2017.

Central Intelligence Agency (2015d). Brazil. Central Intelligence Agency. 18 August 2017.

Central Intelligence Agency (2015e). India. Central Intelligence Agency. 18 August 2017.

Conrad, P. (1999). Modern times, modern places. New York: Thames \& Hudson.

Davis, M. (2006). Planet of slums. New York: Verso.

Denton, J. A. (1990). Society and the official world: A reintroduction to sociology. Dix Hills: General Hall. 
Ehrhardt, H., \& Kroll, T. (2012). Energie in der modernen Gesellschaft. Zeithistorische Perspektiven. Göttingen: Vandenhoeck \& Ruprecht.

Eriksen, T. H., \& Nielsen, F. S. (2001). A history of anthropology. Stockholm: Pluto Press.

Esposito, E. (2007). Die Fiktion der wahrscheinlichen Realität. Frankfurt am Main: Suhrkamp.

FAO. (2017). The future of food and agriculture: Trends and challenges. Rome: FAO.

Gleick, J. (1999). Faster: The acceleration of just about everything. New York: Pantheon.

Habitat, U. N. (2003). The challange of slums. Nairobi: Global Report on Human Settlements.

Harari, Y. N. (2017). A brief history of tomorrow. London: Vintage.

Harvey, D. (1989). The condition of postmodernity. Cambridge: Wiley.

Hopkins, D. (2005). Dracunculiasis eradiction: The final inch. The American Society of Tropical Medicine and Hygiene, 73(4), 669-675.

Houscht, M. P. (2016). Indien. Länder Informations Portal. https://www.liportal.de/indien. 10 August 2016.

Huchzermeyer, M. (2014). Troubling continuities-Use and utility of the term slum. In S. Parnell \& S. Oldfield (Eds.), The Routledge handbook on cities of the Global South (pp. 86-96). New York: Routledge.

Jua'rez, A. A., Araujo, A. M., Rohatgi, J. S., \& Filho, O. (2014). Development of the wind power in Brazil: Political, social and technical issues. Renewable and Sustainable Energy Reviews, 39(C), 828-834.

Kiegel, H. (2017). Brasiliens Weg von der aufsteigenden Wirtschaftsmacht zum Krisenland. Geographische Rundschau, 69(4), 22-25.

Kreft, S., Eckstein, D., Dorsch, L., \& Fischer, L. (2015). Global Climate Risk Index 2016. Who suffers the most from extreme weather events? Weather-related loss events in 2014 and 1995 to 2014. Germanwatch Briefing Paper.

Luhmann, N. (1984). Soziale Systeme. Grundriss einer allgemeinen Theorie. Frankfurt am Main: Springer.

Luhmann, N. (1990). Soziologische Aufkla"rung 5: Konstruktivistische Perspektiven. Frankfurt am Main: Springer.

Luhmann, N. (2003). Soziologie des Risikos. Frankfurt am Main: Springer.

Luhmann, N. (2005). Einführung in die Theorie der Gesellschaft. Heidelberg: Carl-Auer Verlag.

Marcotullio, P. J. (2004). Why the Asian urbanization experience should make us think differently about planning approaches. In A. Sorensen, P. J. Marcotullio, \& J. Grant (Eds.), Towards sustainable cities. East Asian, North American and European perspectives on managing urban regions (pp. 3859). Aldershot: Ashgate.

Marcotullio, P. J., Rothenberg, S., \& Nakahara, M. (2005). Globalization and the environmental transitions: Comparison of New York's and Tokyo's experiences. In H. W. Richardson \& C. H. Bae (Eds.), Globalization and urban development, advances in spatial science (pp. 289-310). Berlin: Springer.

Medjedovic', I. (2014). Sekundäranalyse in der quantitativen Forschung. In I. Medjedovic' (Ed.), Qualitative Sekundäranalyse (pp. 27-47). Wiesbaden: Springer.

OECD. (2006). Environmental performance reviews. Paris: OECD Publishing.

Parry, J. E., Echeverria, D., Dekens, J., \& Maitima, J. (2012). Climate risks, vulnerability and governance in Kenya: A review. Climate Risk Management Report November 2012. New York: UNDP.

Rosa, H. (2005). Acceleration. The change in temporal structures in modernity. Berlin: Suhrkamp. 
Rosa, H. (2010). Alienation and acceleration: Towards a critical theory of late-modern temporality. Frankfurt am Main: Suhrkamp.

Rostow, W. W. (1991). The stages of economic growth: A noncommunist manifesto. Cambridge: Cambridge University Press.

Schmidt, M., \& Pearson, O. (2016). Pastoral livelihoods under pressure: Ecological, political and socioeconomic transitions in Afar (Ethiopia). Journal of Arid Environments, 124(1), 22-30.

Sobsey, M. (2002). Managing water in the home: Accelerated health gains from improved water supply. New York: WHO.

The World Bank (2017). World development indicators. http://data.worldbank.org/datacatalog/world-development-indicators 15 August 2017.

Umweltbundesamt (2011). Stickstoff - Zuviel des Guten? Berlin.

UN (2016). The Sustainable Development Goals Report 2016. http://unstats.un.org/sdgs/report/2016/The\%20Sustainable\%20Development\%20Goals\%20Re port\%202016.pdf. 01 August 2016.

UNDP (2016). Clean water and sanitation: Why it matters. http://www.un.org/sustainabledevelopment/wp-content/uploads/2016/08/6_Why-itMatters_Sanitation_2p.pdf 12 June 2016.

UNFCCC (2015). Adoption of a protocol, another legal instrument, or an agreed outcome with legal force under the Convention applicable to all Parties. http://unfccc.int/resource/docs/2015/cop21/eng/da01.pdf. 25 June 2016.

UNICEF (2015). Why sustainable energy matters to children: The critical importance of sustainable energy for children and future generations.

UN Expert Group (2008). Preparing for sustainable urban growth in developing areas. Department of Economic and Social Affairs, UN/POP/EGM-URB/2008/02. New York: United Nations.

UN Habitat (2016a). Urbanization and development: Emerging futures. World Cities Report 2016. New York.

UN Habitat (2016b). Structural transformation in developing countries: Cross regional analysis. http://unhabitat.org/books/structural-transformation-in-developing-countriescross- regionalanalysis/. 14 June 2016.

WBGU (2003). Welt im Wandel. Energiewende zur Nachhaltigkeit. Berlin. http://www.wbgu.de/fileadmin/templates/dateien/veroeffentlichungen/hauptgutachten/jg 2003/wbgu_jg2003.pdf. 24 July 2016.

WHO. (2016). Burning opportunity: Clean household energy for health, sustainable development, and wellbeing of women and children. Geneva: WHO.

WHO, \& UNICEF. (2015). 25 Year. Progress on sanitation and drinking water. 2015 Update and MDG Assessment. Geneva: WHO.

Whittaker, H. D., Zhu, T., Sturgeon, T. J., Tsai, M. H., \& Okita T. (2008). Compressed development. MIT IPC Working Paper Series 08-005. Cambridge: MIT.

World Population Review (2017). Lagos population 2017. http://worldpopulationreview.com/worldcities/lagos-population. 25 February 2017). 